\title{
Influence of Swimming Pool Design on Hydraulic Behavior: A Numerical and Experimental Study
}

\author{
Anaëlle Cloteaux ${ }^{1,2}$, Fabien Gérardin $^{1^{*}}$, Noël Midoux ${ }^{2}$ \\ ${ }^{1}$ Department of Process Engineering, National Institute of Research and Safety (INRS), Vandoeuvre, France \\ ${ }^{2}$ Laboratory of Reactions and Process Engineering (LRGP), National Center of Scientific Research (CNRS), \\ University of Lorraine, Nancy, France \\ Email: * fabien.gerardin@inrs.fr
}

Received February 15, 2013; revised March 8, 2013; accepted March 15, 2013

Copyright (C) 2013 Anaëlle Cloteaux et al. This is an open access article distributed under the Creative Commons Attribution License, which permits unrestricted use, distribution, and reproduction in any medium, provided the original work is properly cited.

\begin{abstract}
A swimming pool can be considered as a chemical reactor with specific hydraulic and macro-mixing characteristics. The nature of flow into the pool depends on various characteristics, such as water inlets and outlets (number and position), pool geometry, and flow rate. This study investigates how swimming pool design affects hydraulic behavior based on experimental and computational fluid dynamics studies (CFD). This paper does not describe the hydraulic behavior of all existing swimming pools, however the cases studied here are representative of pool designs widely used in Europe and the United States. The model developed, based on the principle of a stirred reactor, could be used as a first approach in describing the hydraulic behavior of regular pools. This model is suitable for the study of physical and chemical phenomena with long characteristic times. Other, more advanced, models were shown to be more suitable to the case of fast chemical processes.
\end{abstract}

Keywords: Computational Fluid Dynamics (CFD); Hydraulic Model; Residence Time Distribution (RTD); Swimming Pool; Velocity Field, Tracer

\section{Introduction}

Bacterial and chemical water quality in swimming pools is regulated by precise and stringent guidelines set out by the World Health Organization (WHO) and most national authorities [1]. Health authorities in many countries are very concerned about identifying and quantifying chlorination by-products [2]. In the relevant literature, most reports describe monitoring results of different chemical species in pools over time; kinetics of by-products formation, on-site studies, are not available [3,4]. However, a couple of laboratory-based kinetic studies of chloramines formation have been proposed $[5,6]$. The highly complex chemistry of chloramines formation is an obstacle to deeper knowledge in this field, especially for the development of predictive kinetic models applicable in real situations. Another problem is widespread lack of understanding of hydraulic behavior in pools, which has been treated by very few studies $[7,8]$. A swimming pool can be considered as a chemical reactor, but with specific hydraulic and macro-mixing characteristics like those

${ }^{*}$ Corresponding author. used for kinetic study. Knowledge of micro-mixing in such large systems is not necessary given the kinetic time constants $[5,6]$.

There are no universal standards governing swimming pool design. The nature of flow in pools depends on various characteristics, such as the number and the position of water inlets and outlets, pool geometry, and feed flow. The International Swimming Federation (Fina) only imposes geometries for regional, national and international competitions, without specifying any feature related to the number of water inlets and outlets [9]. Design rules are proposed in the United States, but these differ from one state to another [10]. In Europe, Switzerland proposes the most detailed regulations in terms of engineering [11].

Swiss standards state that flow recirculation must be reversed (reversed hydraulics), i.e., that water should be supplied to the pool by inlets in both longitudinal vertical walls or in the bottom of the pool. Outlets must be designed as overflow channels around the pool perimeter. The standards also specify inlet spacing, as well as the turnover period. 
The first part of this paper studies French experimental pool designed without specific hydraulic rules as almost pools in France. This type of pool operates under a mixed water recirculation regime (mixed hydraulics) i.e., based on the principle that $50 \%$ of the total flow circulates through outlets in the pool bottom, and 50\% through overflow channels. This work consisted in determining hydraulic characteristics (velocity field, stream lines and the corresponding residence time distribution (RTD)) for this pool using both computational fluid dynamics (CFD) and experimental studies. The study was performed in the absence of swimmers although their presence is known to affect the overall hydrodynamic behavior. This approach aims to validate by tracer-based experiments the hydrodynamic parameters obtained by the simulation. The work was then extended to the study of various pools, not only those designed according to Fina and Swiss recommendations, but also pools whose design differs by various degrees from the recommendations outlined by Swiss standards. This section of the work presents numerical simulations of velocity field, streamlines, and RTD. Finally, although not exhaustive, this investigation provides important information on the hydraulic behavior encountered for most of pool designs encountered all over the world.

The expected results of this work should give some essential elements for good practices in pool design. The optimization of pool hydraulic operation should reduce dead volumes and improve disinfection efficiency. Moreover this study produces specific knowledge for kinetic approach aiming prediction of disinfection by-products formation.

\section{Material and Methods}

\subsection{Experimental pool}

The experimental pool $(25 \mathrm{~m} \times 10 \mathrm{~m})$ has a depth of 0.9 $\mathrm{m}$ in the shallow end and $2 \mathrm{~m}$ in the deep end. The total volume is $377 \mathrm{~m}^{3}$. The pool is fed with water via three square-cross-section inlets in the wall at the shallow end, and two in each long vertical wall (Figure 1). Total inlet flow is $5.28 \times 10^{-2} \mathrm{~m}^{3} \cdot \mathrm{s}^{-1}$. The pool operates in mixed hydraulics mode: water is collected at the surface by two overflow channels located in the two long sides, and by one square outlet at the bottom of the pool. The water recirculation turnover period for the experimental pool is $\tau=7140 \mathrm{~s}$, or $1.98 \mathrm{~h}$.

The inlet water flow is distributed as follows:

- Inlets $a=3.17 \times 10^{-2} \mathrm{~m}^{3} \cdot \mathrm{s}^{-1}$;

- Inlets $b=5.2 \times 10^{-3} \mathrm{~m}^{3} \cdot \mathrm{s}^{-1}$;

- Inlets $c=1.59 \times 10^{-2} \mathrm{~m}^{3} \cdot \mathrm{s}^{-1}$.

The pool operates in a closed loop i.e., water leaving the pool is reintroduced. The flow rate leaving the pool from the bottom is $2.64 \times 10^{-2} \mathrm{~m}^{3} \cdot \mathrm{s}^{-1}$. This requires the presence of a buffer tank (Figure 2). The flow rate for water circulating through the buffer tank from the overflow channels is $2.64 \times 10^{-2} \mathrm{~m}^{3} \cdot \mathrm{s}^{-1}$. The buffer tank has a volume of about $V_{B T}=9.5 \mathrm{~m}^{3}$; the corresponding mean residence time in the buffer tank is $t_{B T}=360 \mathrm{~s}$. The buffer tank is usually used to compensate for variations in pool volume due to the number of swimmers present.

\subsection{Designed Pools}

The geometries of pools studied here were those of Olympic pool $(50 \mathrm{~m} \times 21 \mathrm{~m} \times 1.8 \mathrm{~m})$ used for national and international competitions, and those of smaller pools $(25 \mathrm{~m} \times 15 \mathrm{~m} \times 1.6 \mathrm{~m})$, known as learning pools, which is used for non-competitive swimming and regional competitions [9].

The geometry and hydraulics of each pool (Olympic or learning) is shown in Table 1 and Figures 3 and 4. After the initial study of pools designed according to the Swiss standards, investigations were extended to pools operating under a mixed water-recirculation regime (mixed hydraulics) featuring two or four overflow channels. The water recirculation turnover period for all configurations studied was 3 hours, in line with WHO recommendations [1].

The pool volumes studied were $600 \mathrm{~m}^{3}$ (learning pools) and $1890 \mathrm{~m}^{3}$ (Olympic pools). Water inlets were square-

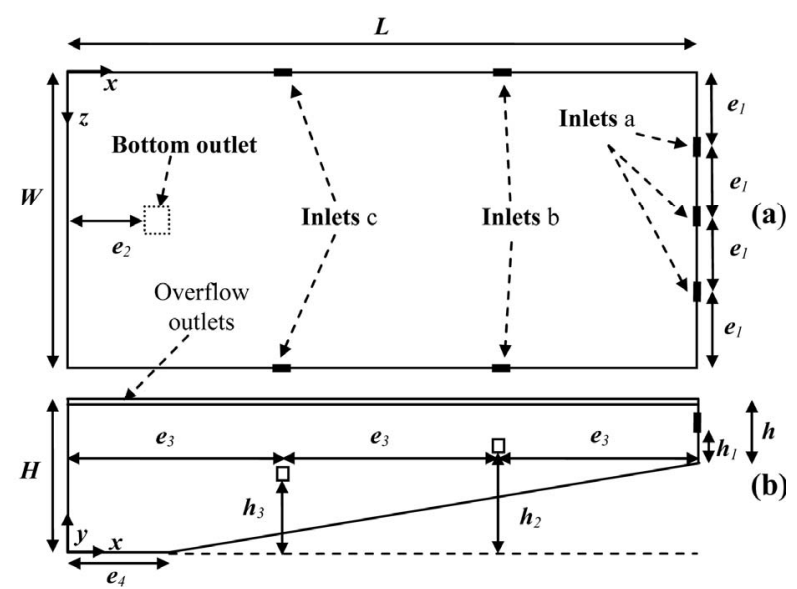

Figure 1. Geometric characteristics of the experimental pool. (a) Top view; (b) Side view. $L=25 \mathrm{~m} ; W=10 \mathrm{~m} ; H=2 \mathrm{~m} ; h$ $=0.8 \mathrm{~m} ; e_{1}=2.50 \mathrm{~m} ; e_{2}=2.60 \mathrm{~m} ; e_{3}=8.30 \mathrm{~m} ; h_{1}=0.25 \mathrm{~m}$; $h_{2}=0.95 \mathrm{~m} ; h_{3}=0.55 \mathrm{~m} ; S_{\text {Inlet a }}=0.0577 \mathrm{~m}^{2} ; S_{\text {Inlet b }}=0.0189$ $\mathrm{m}^{2} ; S_{\text {Inlet c }}=0.0577 \mathrm{~m}^{2} ; S_{\text {Outlet bottom }}=0.1696 \mathrm{~m}^{2}$.

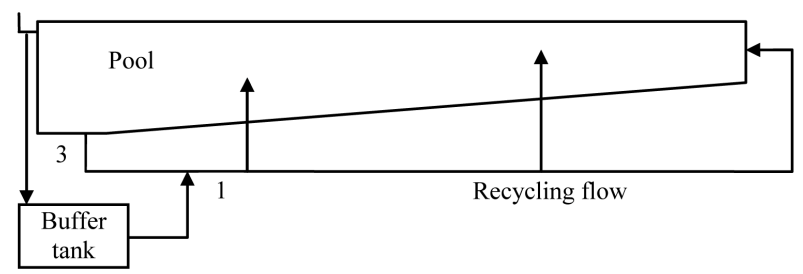

Figure 2. Experimental system. 
Table 1. Pool dimensions and characteristics.

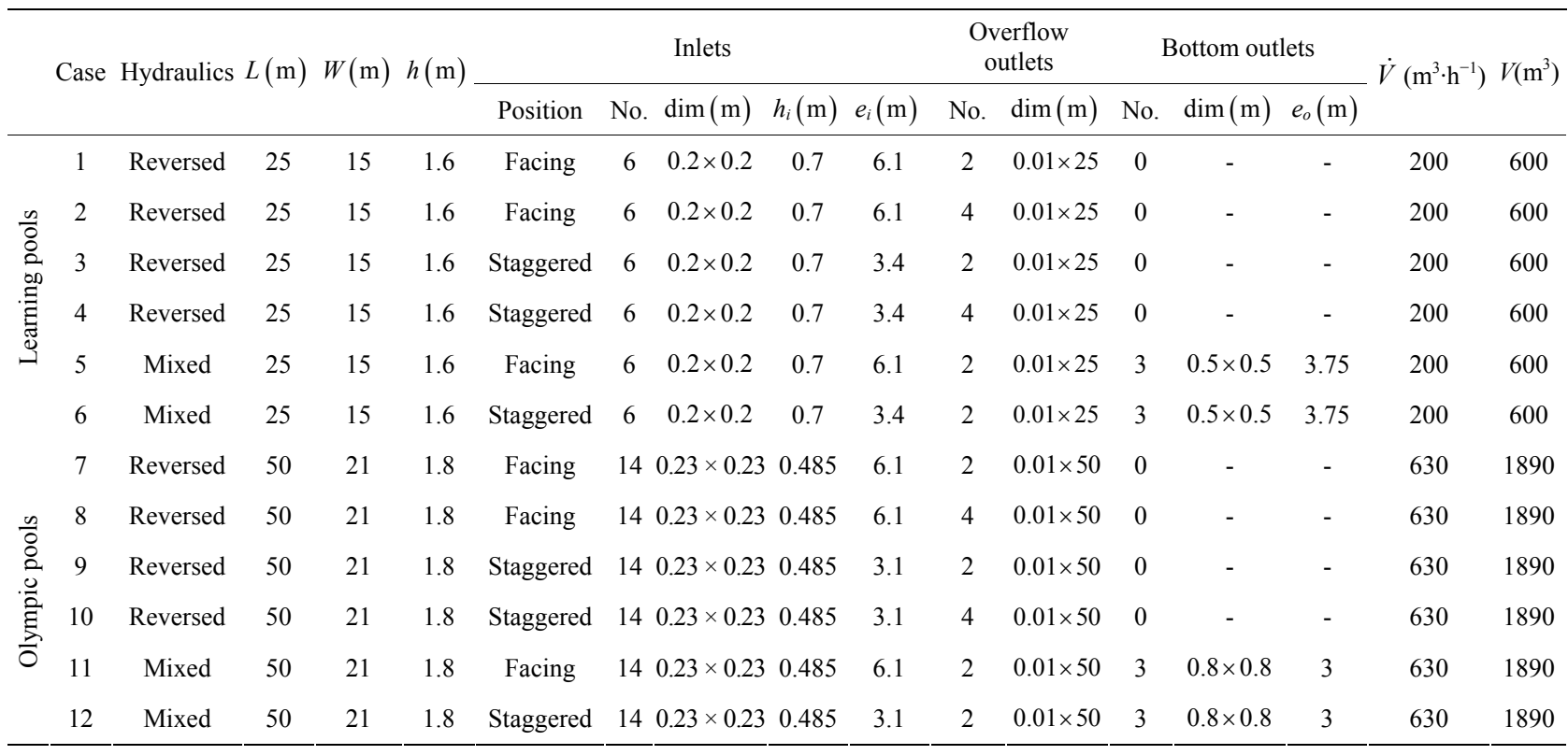

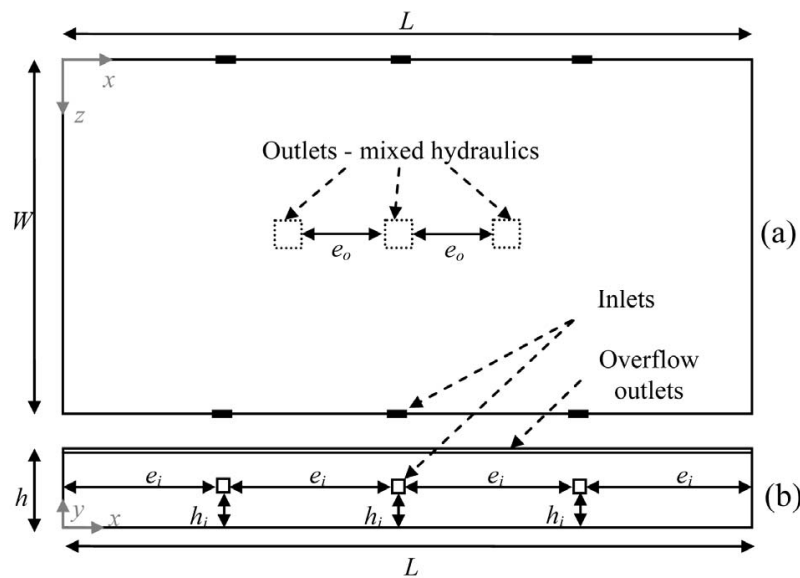

Figure 3. Geometric characteristics of a pool with facing inlets: (a) Top view; (b) Side view.

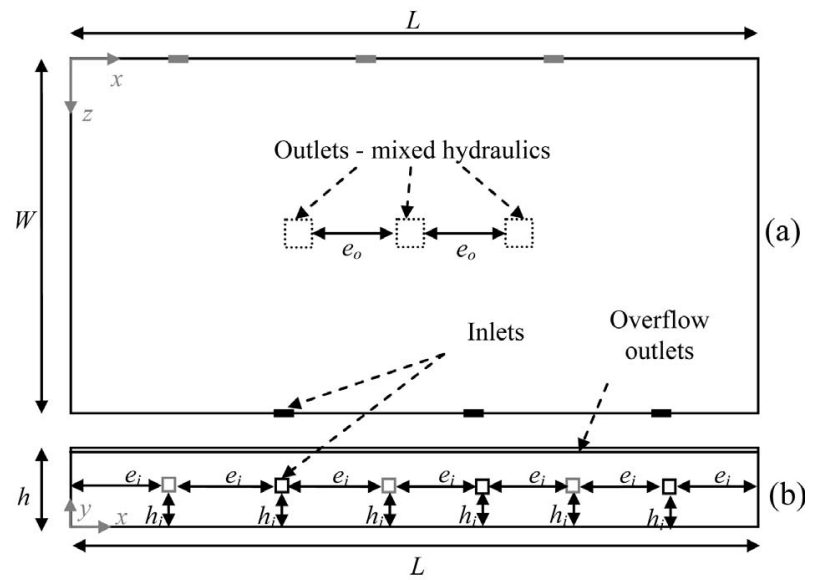

Figure 4. Geometric characteristics of a pool with staggered inlets: (a) Top view; (b) Side view. cross-sections located in the two longer vertical walls. Inlet flow was $5.60 \times 10^{-2} \mathrm{~m}^{3} \cdot \mathrm{s}^{-1}$ in learning pools, and $1.75 \times 10^{-1} \mathrm{~m}^{3} \cdot \mathrm{s}^{-1}$ in Olympic pools. For pools operated under reversed hydraulics, water was collected at the surface through $0.01 \mathrm{~m}$ thick overflow channels. For pools performing under mixed hydraulics, in addition to overflow channels, water was also collected through three square outlets in the bottom of the pool.

Pools were studied in two operating modes. In the first mode the pool is operated in open circuit (open loop), without a buffer tank. In this case, water leaving the pool is not reintroduced. RTD was calculated on the basis of this operating mode. The second operating mode is based on full water recycling (closed loop), i.e., water leaving the pool is reintroduced. This is the most common operating mode found in pools, and all the pools studied here had a buffer tank. For pools operated under mixed hydraulics, water flow circulating through the buffer tank comes only from the overflow channels. In reversed hydraulics, the buffer tank is fed by the total recycling flow. The buffer tank volume is defined according to the Swiss guidelines, but the effective water volume in the absence of swimmers represents around one third of the total buffer tank volume (Table 2).

\subsection{Experiment}

The hydraulic of the experimental pool was characterized by introducing an inert tracer into the inlet flow as a single pulse. The tracer used was yttrium in $2 \%$ nitric acid solution (Sigma Aldrich, $10 \mathrm{~g} \cdot \mathrm{L}^{-1}$ of $\mathrm{Y}^{3+}$ ). About $2 \mathrm{~g}$ of this compound was injected into the inlet flow feeding inlets a, b and c (point 1 in Figure 2). The tracer concen- 
Table 2. Water volume $\left(V_{B T}\right)$ and mean residence time $\left(\tau_{B T}\right)$ in buffer tank

\begin{tabular}{ccccc}
\hline & Hydraulics & $\begin{array}{c}\text { Overflow } \\
\text { outlets }\end{array}$ & $V_{B T}\left(\mathrm{~m}^{3}\right)$ & $\tau_{B T}(\mathrm{~s})$ \\
\hline \multirow{2}{*}{$\begin{array}{c}\text { Learning } \\
\text { pools }\end{array}$} & Reversed & 2 & 15.4 & 88 \\
& Mixed & 2 & 19.9 & 227 \\
& Reversed & 4 & 17.6 & 100 \\
$\begin{array}{c}\text { Olympic } \\
\text { pools }\end{array}$ & Reversed & 2 & 10.8 & 194 \\
& Mixed & 2 & 12.4 & 445 \\
\hline
\end{tabular}

tration was measured at points 1, 2 and 3 by sampling about $50 \mathrm{~mL}$ water stabilized by $100 \mu \mathrm{L}$ nitric acid $\left(0.3 \mathrm{~mol} \cdot \mathrm{L}^{-1}\right)$ every $5 \mathrm{~min}$ during the first half hour, and then every $10 \mathrm{~min}$ up to the end of the experiment. This allowed measuring how tracer concentration evolved over time at these points. The inlet and outlet pipe volumes, representing less than $1 \%$ of the total pool volume, were neglected when interpreting results. Yttrium was analyzed by Inductively Coupled Plasma-Atomic Emission Spectrometry (ICP-AES).

\subsection{Flow Simulation}

Flow simulation allows the velocity field, path-lines, RTD and segregation intensity $\left(I_{S}\right)$ to be determined for the pool. Simulations were performed in the absence of swimmers for experimental and designed pools. RTD provides information on the nature of the reactor (plug flow, Continuous Stirred Tank Reactor (CSTR), or a various combinations of the two), and indicates the existence of a short-circuit or dead zone. In addition, segregation intensity provides information on the concentration distribution (mixing quality) for a species in the system volume.

CFD simulations are used to determining flow behavior in tank or reactor [12,13]. ANSYS FLUENTC was used in this study for CFD calculations, this software is based on the finite volume method. Model equations were solved for each control volume, conserving the relevant quantity (mass, momentum, tracer concentration, etc.). The Upwind first-order method was used to solve the differential equations governing fluid flow. Pressure and velocity were coupled with a SIMPLE scheme.

\subsubsection{Turbulence Model}

The Reynolds number for the inlet jet is:

$$
\mathrm{Re}=\frac{\rho u d_{h}}{\mu}
$$

where $u$ is the inlet velocity and $d_{h}$ is inlet nozzle hy- draulic diameter. For the pools studied, the Reynolds number for the inlet je5t was about $5 \times 10^{4}$, but very low velocities were simulated in some areas. To compensate for non-uniform distribution of velocity, the "ReNormalization Group" (RNG) $k-\varepsilon$ turbulence model was chosen. RNG theory provides an analytically derived differential equation to model effective viscosity, taking low Reynolds number effects into account. This improved the model's performance for low Reynolds numbers and near-wall flows. The coefficients for the RNG $k$ - $\varepsilon$ model were $C_{1}=1.42, C_{2}=1.68, C_{\mu}=0.0845 \quad$ [14].

\subsubsection{Numerical Grid}

For pools with facing inlets, flow field simulation was conducted over a quarter of the pool area. For pools with staggered inlets, the whole pool area had to be studied. A hexahedral grid was applied using Gambit ${ }^{\circ}$ software. Cell dimensions are given in Table 3. The grid is composed of between 20,000 and 800,000 cells.

\subsubsection{Boundary Conditions}

Inlet conditions: uniform inlet velocity in $z$ direction. The initial values of $k$ and $\varepsilon$ for inlets are listed in Table 3 The values are calculated with the following equations:

$$
k=1.5(I u)^{2}, \varepsilon=C_{\mu} \frac{k^{2}}{\mu_{T}}
$$

where $I$ is the turbulence intensity, taken as $5 \%$ (value generally observed in flows pipe).

Outlet conditions:

- For reverse hydraulics pools: the outlet pressure is taken at the ambient level ( 0 bar relative pressure).

- For mixed hydraulics pools: the outflow is defined with fixed flow weighting; $50 \%$ by overflow outlets and $50 \%$ by bottom outlets.

- Water surface is a wall with slip condition.

- Pool walls are with no-slip velocity and their roughness was $0.5 \mathrm{~mm}$. The standard wall function approach was applied.

\subsubsection{Residence Time Distribution and Outlet Homogeneity Degree}

The following strategies were used to determine how RTD and homogeneity degree:

1) The equations for momentum conservation and RNG $k$ - $\varepsilon$ turbulence were solved until a steady-state solution was reached.

2) $\mathcal{N}$ moles of liquid inert tracer were added to the inlet flow in one pulse injection. A steady-state flow solution was applied as initialization, the same equations were solved in an unsteady state. Step time was fixed at $0.2 \mathrm{~s}$. The tracer was considered to be a passive scalar, with a diffusivity coefficient of 
Table 3. Grid characteristics and inlet boundary conditions.

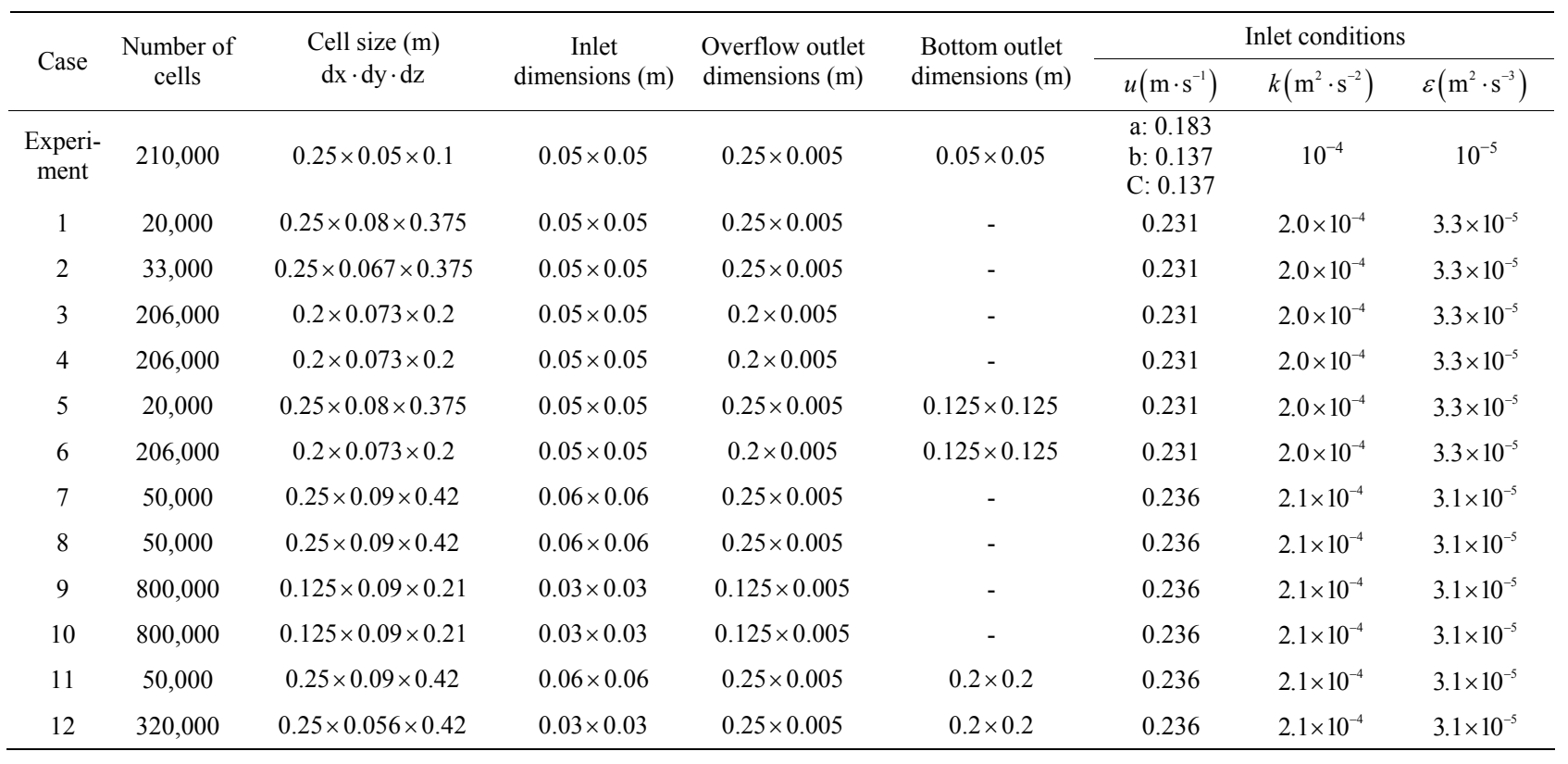

$D=1.02 \times 10^{-9} \mathrm{~m}^{2} \cdot \mathrm{s}^{-1}$ according to yttrium coefficient [15]. The turbulent Schmidt number is $S c_{T}=0.7 \quad$ [16].

In an open loop, the $E(\theta)$ distribution is obtained by measuring the tracer concentration $c(\theta)$ at the pool outlet:

$$
E(\theta)=\frac{c(\theta)}{\mathcal{N} / V}, \theta=\frac{t}{\tau}, \tau=\frac{V}{\dot{V}}
$$

RTD describes the hydrodynamic behavior of real systems, considering its geometry and inlet and outlet conditions. RTD can evidence potential short-circuits or dead volumes. However, it provides no information on the uniformity of tracer concentration in the volume studied.

The RTD values for experimental and designed pools obtained by simulation were compared to those of simple models, such as CSTR. In open loop mode, this corresponds to comparison of the following RTD characteristics:

- Dimensionless average residence time

$$
\bar{\theta}=\mu_{1}
$$

- Variance

$$
\sigma^{2}=\mu_{2}^{\prime}
$$

- Skewness

$$
S k=\mu_{3}^{\prime} / \sigma^{3}
$$

- Kurtosis

$$
K u=\mu_{4}^{\prime} / \sigma^{4}
$$

with

$$
\begin{aligned}
& \mu_{k}=\int_{0}^{\infty} \theta^{k} E(\theta) \mathrm{d} \theta \\
& \mu_{k}^{\prime}=\int_{0}^{\infty}(\theta-\bar{\theta})^{k} E(\theta) \mathrm{d} \theta
\end{aligned}
$$

In a closed loop, the homogeneity degree at the outlet, $U$, is calculated by dividing the tracer concentration at the pool outlet by its steady-state concentration $c^{\text {stat }}$.

$$
U(\theta)=\frac{c(\theta)}{c^{\text {stat }}}
$$

In this case, a user-defined function was set up in FLUENT $^{\mathcal{O}}$ to calculate the total outlet concentration after a given time step. The inlet concentration for the next time step was thus equal to the outlet concentration calculated.

Uniformity of tracer concentration in a system was also evaluated considering the segregation intensity $I_{S}$ and how its variation over time. Segregation intensity is defined as the ratio of the standard deviation to the average concentration of pool tracer concentration. This allowed the pool mixing time to be determined.

Thus, for $n$ cells of grid:

$$
I_{S}(\theta)=\frac{1}{\bar{c}} \sqrt{\frac{\sum_{k=1}^{k=n}\left(c_{k}(\theta)-\bar{c}\right)^{2}}{n}}
$$

In all closed loop cases, the degrees of outlet homogeneity for each configuration were compared with each other, and with the CSTR model. This comparison is led by two criteria characterizing mixing. The first one, $\theta_{\mathrm{U} 5 \%}$ refers to pool outlet concentration and is defined as:

$$
\forall \theta>\theta_{U 5 \%}, U(\theta)<0.05
$$

The second criterion, $\theta_{I S 5 \%}$, concerns segregation in- 
tensity in the pool. $\theta_{I S 5 \%}$ is defined as:

$$
\forall \theta>\theta_{I S 5 \%}, I_{S}(\theta)<0.05
$$

\section{Results and Discussion}

\subsection{Experiment}

Evolution of tracer concentration over time $(U(\theta))$ measured both for outlets (bottom and overflow channels) and in the feed flow of the pool is shown in Figure 5. It appears that the inlet concentration increases rapidly before stabilizing at about $\theta=0.4$ or $t=2856 \mathrm{~s}$. However, the overflow channel concentration indicates a subdamped signal, where the tracer concentration in the bottom outlet seems over-damped. From $\theta=0.5$, an apparently stable, significant difference is observed between concentrations measured in overflow channels and those measured in the bottom outlet. This difference can probably be explained by the presence of a dead zone or a very slightly mixed volume in the vicinity of the bottom outlet. Flow simulation should enable us to confirm this hypothesis.

\subsection{Numerical Simulation}

The equations governing flow field were solved in steady-state conditions with residual convergence criteria of $10^{-3}$.

\subsubsection{Experimental Pool}

CFD for the experimental pool indicates the presence of jets at each inlet (Figure 6) inducing large vortices (Figure 7). These vortices have a significant area of the pool,

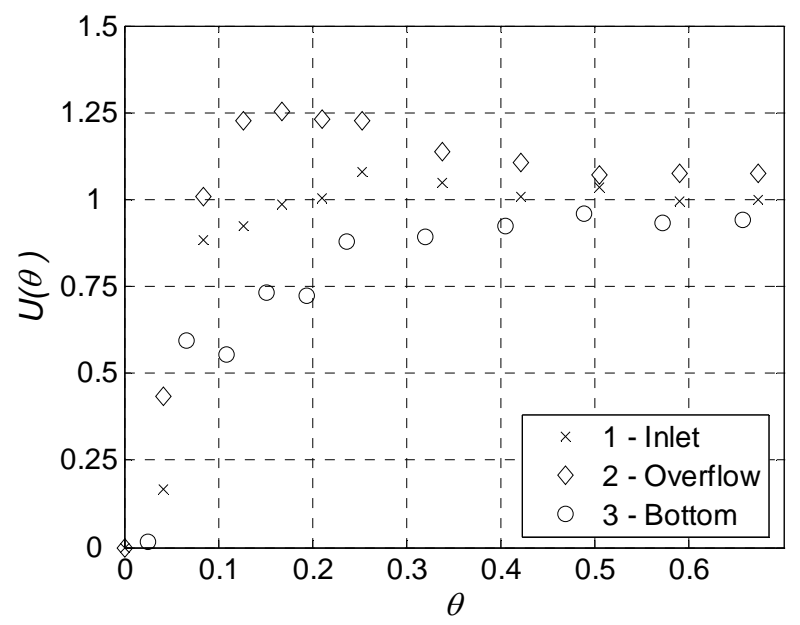

Figure 5. Outlet homogeneity degree in closed loop configuration for experimental case at points 1, 2 and 3 (Figure 2).
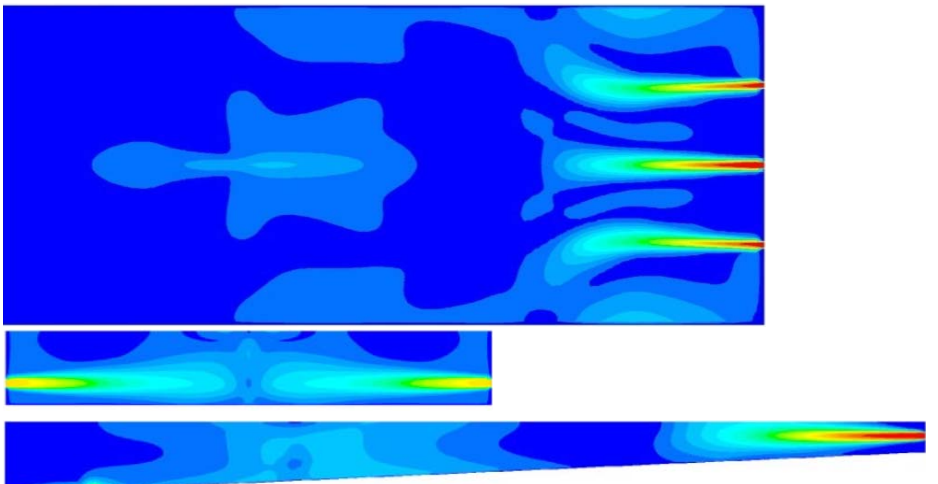

Figure 6. Velocity magnitude contours $\left(\mathrm{m} \cdot \mathrm{s}^{-1}\right)$ in the experimental pool at $y=1.6 \mathrm{~m}, x=8 \mathrm{~m}$ and $z=5 \mathrm{~m}$.
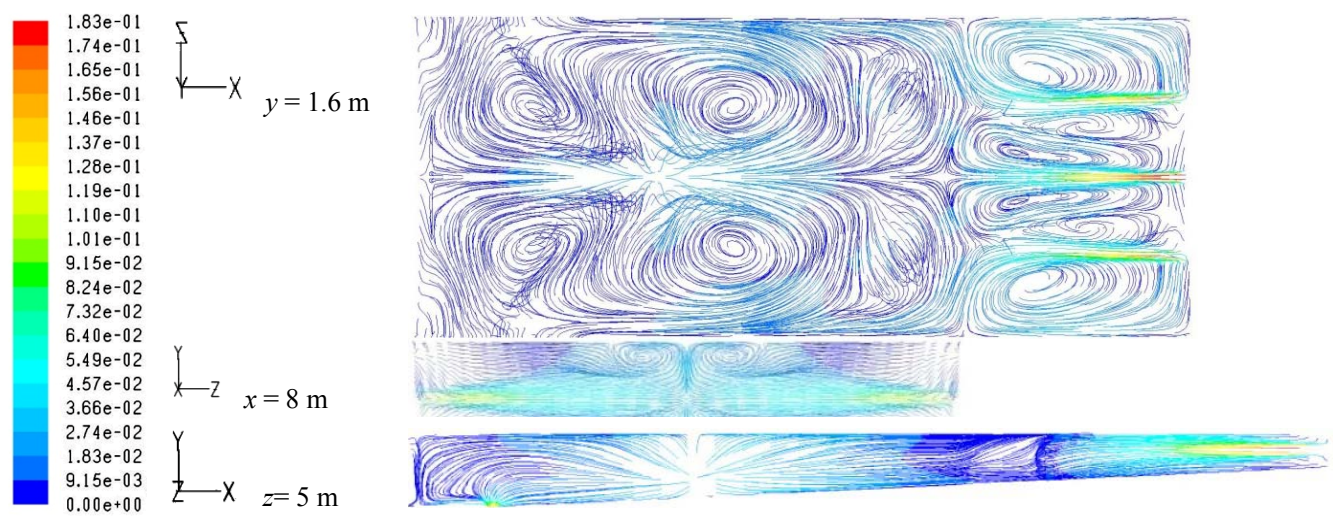

Figure 7. Path-lines coloured according to velocity magnitude $\left(\mathrm{m} \cdot \mathrm{s}^{-1}\right)$ in the experimental pool at $y=1.6 \mathrm{~m}, x=8 \mathrm{~m}$ and $z=5 \mathrm{~m}$. 
and contribute to extensive water mixing. However, some isolated areas appear to be less intensively mixed, particularly near the bottom outlet close to the end of the pool (Figure 8). These areas are mainly observed in pools with facing inlets in the long sides. In the case that the jets are formed opposite to each other, and merge in the central part of the pool, water is not allowed to circulate from one end of the pool to the other. These observations support the assumption that dead zone in the pool explains the differences in tracer concentration measured in the overflow and at the bottom outlets of the experimental pool.

Simulation of the RTD based on resolution of the tracer flow shows a delay followed by a major shortcircuit (Figure 9). This short-circuit appears at $\theta=0.05$ for both $E(\theta)$ (Figure 9(a)) and $U(\theta)$ (Figure 9(b)). In a closed loop configuration, the oscillations of outlet homogeneity degree produced by this short-circuit are rapidly damped by the large volume of the pool. $U(\theta)$ values predicted by simulation are very close to the experimentally determined values, although the short-circuit was not observed in experiments. This difference may be due to too low frequency of the water sampling operation. Simulations of $E(\theta)$ and $U(\theta)$ variations over time for the experimental pool are superimposed on values for a CSTR from $\theta=0.25$.
Segregation intensity was determined over time for the experimental pool (Figure 10): it was found to be close to $10 \%\left(\theta_{I S 10 \%}\right)$ at $\theta=0.9$, and $5 \%\left(\theta_{I S 5 \%}\right)$ at $\theta \approx 1.2$. Thus, acceptable mixing of this pool is obtained for $\theta \approx 1$, i.e., after $7140 \mathrm{~s}$.

\subsubsection{Designed Pools}

The horizontal velocity planes at inlet height were determined for two Olympic pools (Figures 11 and 12). One of these pools had facing water inlets (Case 7), while the other had staggered water inlets (Case 9). It appears that staggered inlets contribute to better flow recirculation in the pool, preventing pool segmentation and partitioning. With facing inlets, jets emerge and meet in the center of the pool, creating effective barriers not allowing fluid to circulate freely between pool areas. However, since each recirculation area has its own outlet, the various flows could be expected to be mixed efficiently.

Tracer concentration was monitored after the initial pulse at all pool inlets in open loop mode. In addition to the graphical representation, the simulation allows the mixing characteristics of the studied pools to be assessed, based on the tracer concentration measured. The mass fraction of tracer at $\theta=0.1$ and at $y=0.6 \mathrm{~m}$ for Cases 7 and 9 is shown in Figure 13.
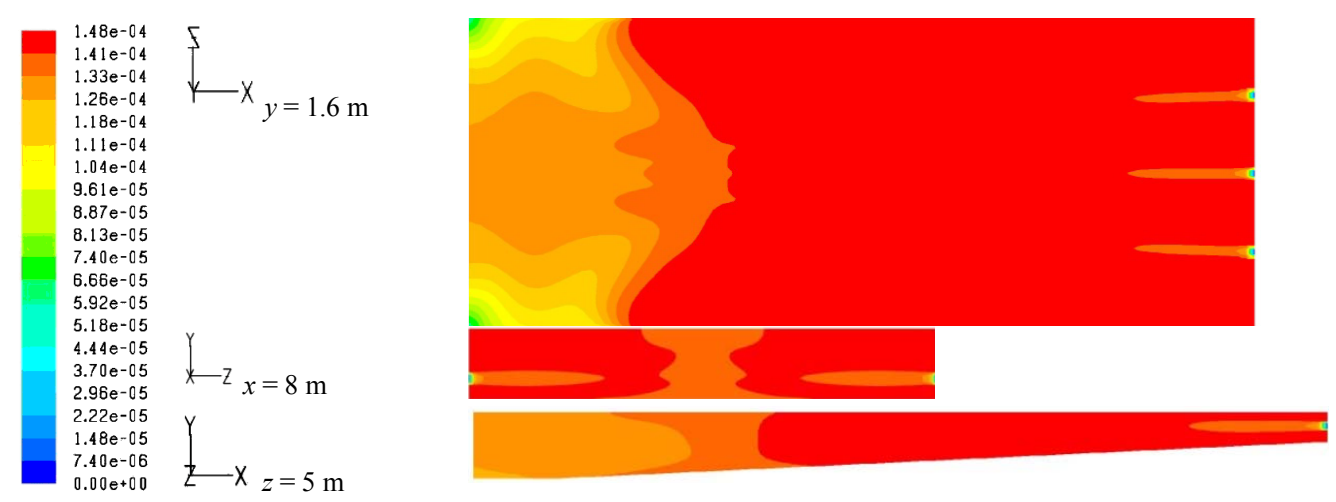

Figure 8. Mass fraction of tracer at $\theta=0.1$ in the experimental pool at $y=1.6 \mathrm{~m}, x=8 \mathrm{~m}$ and $z=5 \mathrm{~m}$.

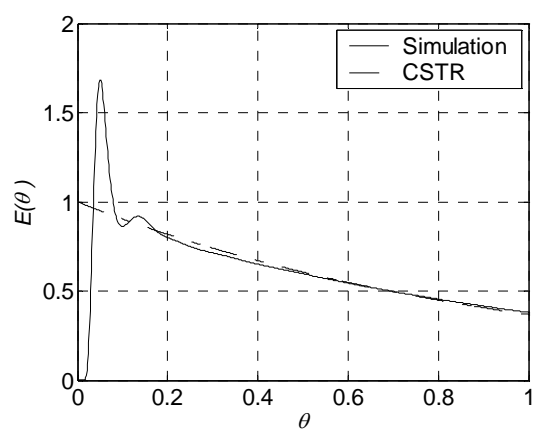

(a)

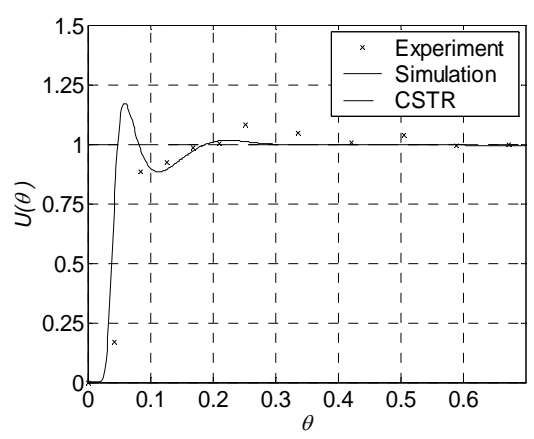

(b)

Figure 9. (a) Simulated residence time distribution in open loop configuration $(E(\theta))$; (b) Outlet homogeneity degree in closed loop configuration $(U(\theta))$ for the experimental pool (experiment and simulation). 


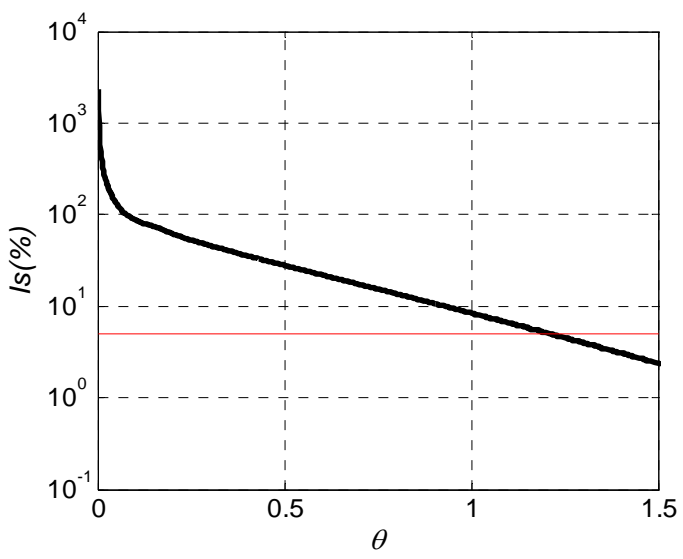

Figure 10. Segregation intensity in closed loop configuration for the experimental pool.

\subsubsection{Residence Time Distribution}

RTD was simulated for different pool configurations (Figure 14). RTD for all the configurations studied reveals an exponential decrease after $\theta=0.3$. Differences between pools operated in reversed hydraulics and those operated in mixed hydraulics are clearly visible in Figure 14. The RTD for pools with reversed hydraulics shows low-magnitude oscillations for $\theta$ ranging from 0.1 to 0.3. A sharp RTD peak is observed at around $\theta=0.02$ for mixed hydraulics pools. This corresponds to a short-circuit between vertical inlets and bottom outlets.

To understand how mixed hydraulics affects pool operation, the signals at overflow outlets, bottom outlets and the overall RTD are represented as:

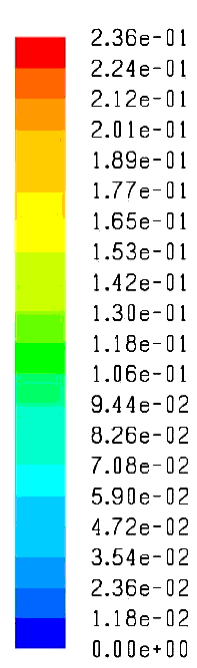

$$
\begin{gathered}
\text { (a) } x \longrightarrow y=0.6 \mathrm{~m} \\
y_{z} x=25 \mathrm{~m} \\
\text { (b) } x \longrightarrow y=0.6 \mathrm{~m}
\end{gathered}
$$
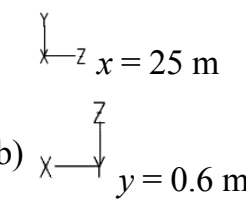
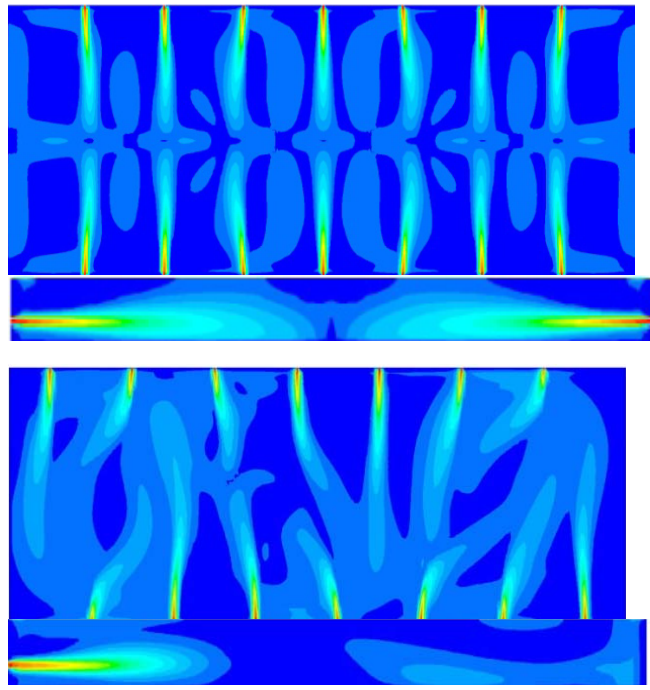

Figure 11. Velocity magnitude contours $\left(\mathrm{m}^{-1} \mathrm{~s}^{-1}\right)$ in two Olympic pools. (a) Case 7, pool with facing inlets at $y=0.6 \mathrm{~m}$ and $x=$ $25 \mathrm{~m}$; (b) Case 9, pool with staggered inlets at $y=0.6 \mathrm{~m}$ and $x=23.4 \mathrm{~m}$.

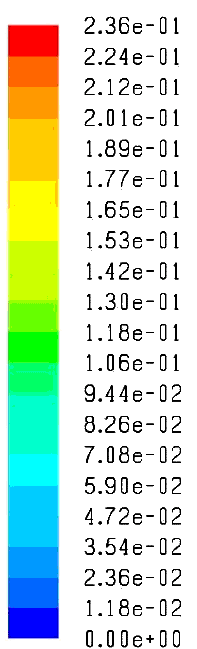

(a)
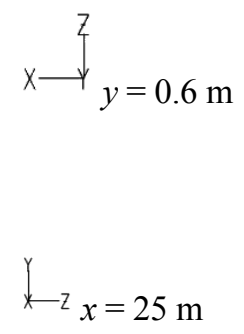

(b)
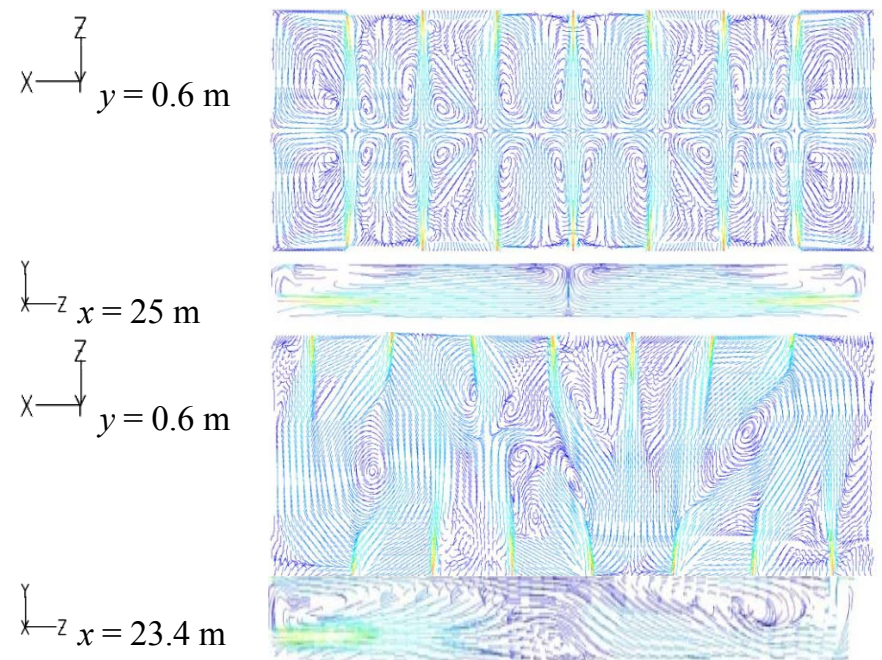

Figure 12. Path-lines coloured according to velocity magnitude $\left(\mathrm{m} \cdot \mathrm{s}^{-1}\right)$ in two Olympic pools; (a) Case 7 , pool with facing inlets at $y=0.6 \mathrm{~m}$ and $x=25 \mathrm{~m}$; (b) Case 9, pool with staggered inlets at $y=0.6 \mathrm{~m}$ and $x=23.4 \mathrm{~m}$. 

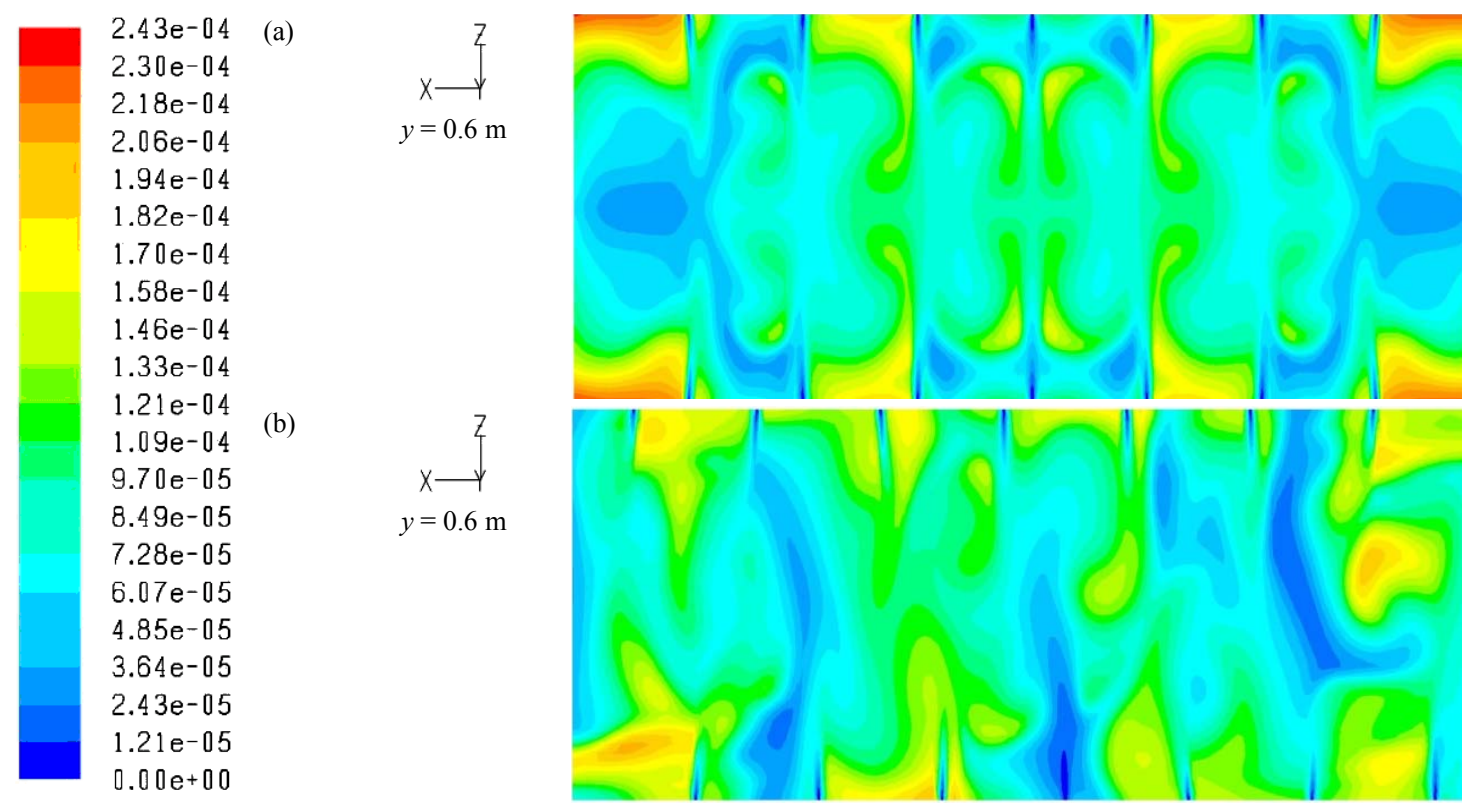

Figure 13. Mass fraction of tracer at $\theta=0.1$ at $y=0.6 \mathrm{~m}$. (a) Case 7, pool with facing inlets; (b) Case 9, pool with staggered inlets.

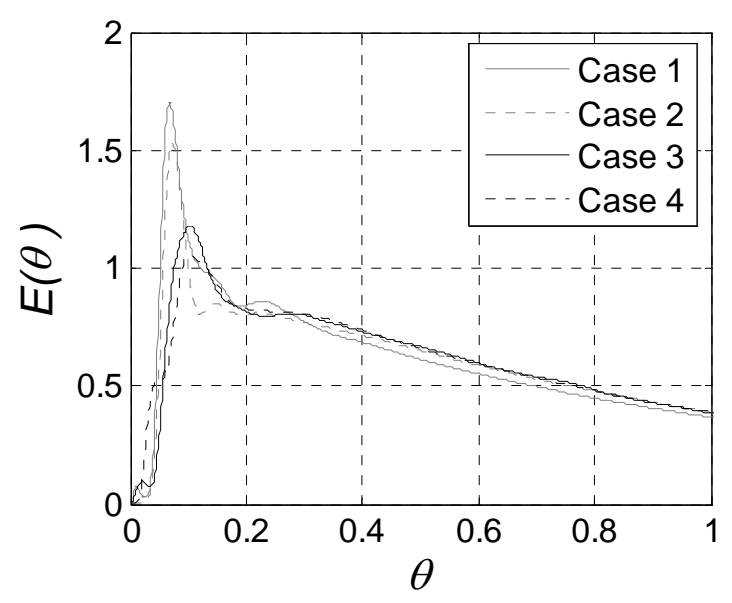

(a)

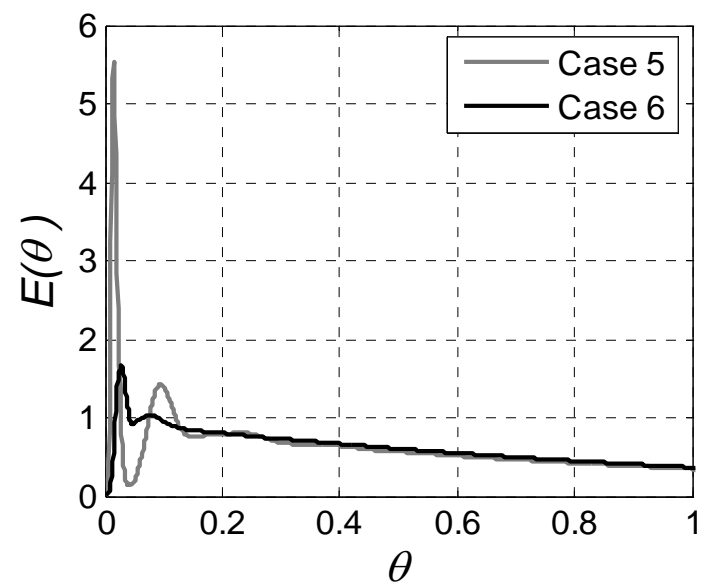

(c)

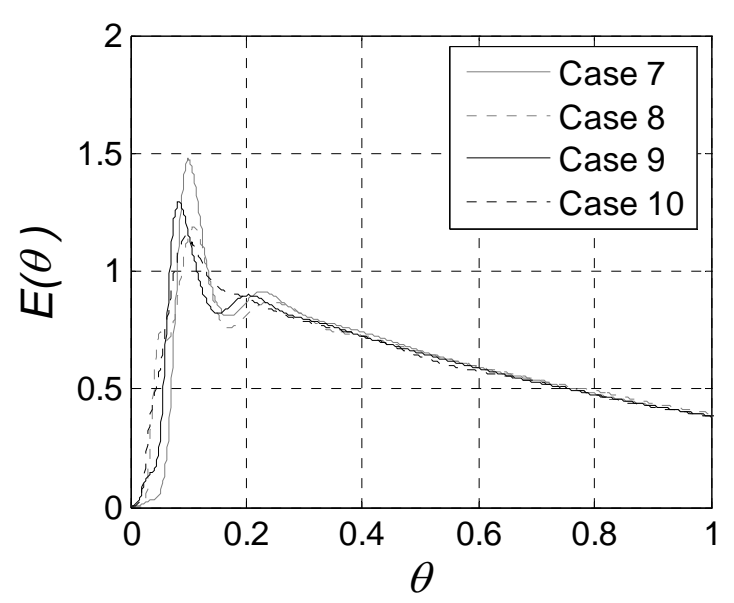

(b)

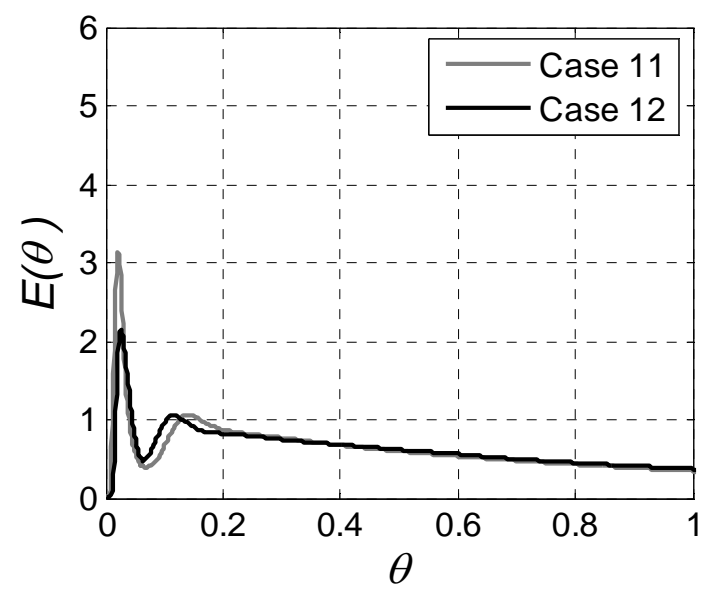

(d)

Figure 14. Residence time distribution in open loop configuration. (a) Learning pools; (b) Olympic pools. 


$$
\begin{aligned}
& E_{\text {overflow }}(\theta)=\frac{c_{\text {overflow }}(\theta)}{\mathcal{N} / V} \\
& E_{\text {bottom }}(\theta)=\frac{c_{\text {bottom }}(\theta)}{\mathcal{N} / V} \\
& E(\theta)=0.5 * E_{\text {overflow }}(\theta)+0.5 * E_{\text {bottom }}(\theta)
\end{aligned}
$$

Bottom outlets produce short-circuit and govern the RTD at short times (Figure 15). For $\theta$ larger than 0.15 , overflow and bottom outlets become equivalent. For mixed hydraulics pools, the short-circuit observed in pools with facing outlets is greater than in pools with staggered outlets.

This can be explained by a shorter average distance between inlets and bottom outlets when inlets are opposite each other.

Mixed hydraulics leads to a short-circuit that can appear more pronounced than with reversed hydraulics. However, it does not significantly modify the mean residence time or other RTD characteristics (Table 4). Irrespective of the configuration, the difference between average residence time and turnover period $(\tau)$ never exceeds $5 \%$. Skewness is positive for all pools, showing that the distribution is concentrated toward the left, and that the right-hand tail is longer. Kurtosis is between 8 and 9 for all pools. Furthermore, based on these results, it appears that the number of overflow channels, or the positions of inlets have little effect on RTD. Despite higher pool dimensions for identical inlet velocity, RTDs for Olympic pools are comparable to those for learning pools.

Considering the RTD characteristics $\left(\bar{\theta}, \sigma^{2}, S k, K u\right)$, hydraulic behavior of all pools (experimental and designed) is very close to CSTR behavior.

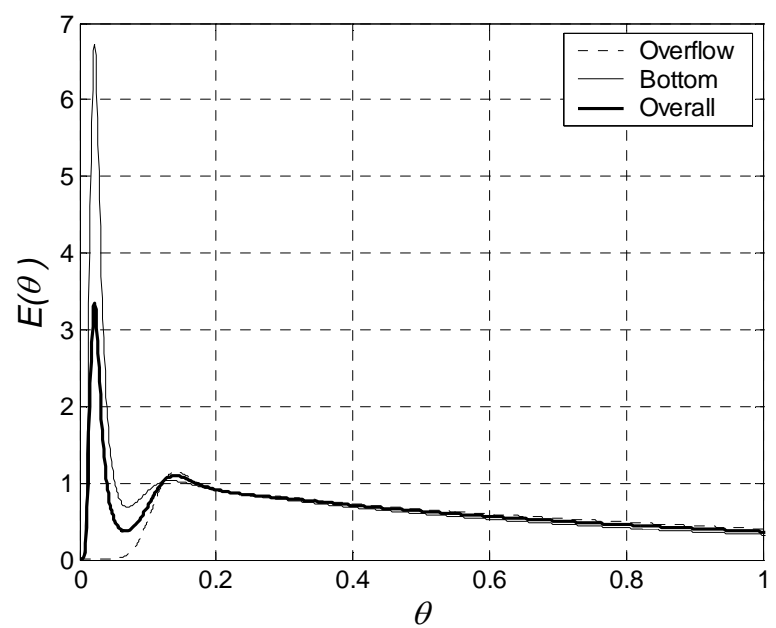

Figure 15. Overall RTD and signals at overflow outlets and bottom outlets for Case 11.

Table 4. Mean residence time, variance, skewness and kurtosis for simulated RTD in open loop configurations calculated over $10 \tau$.

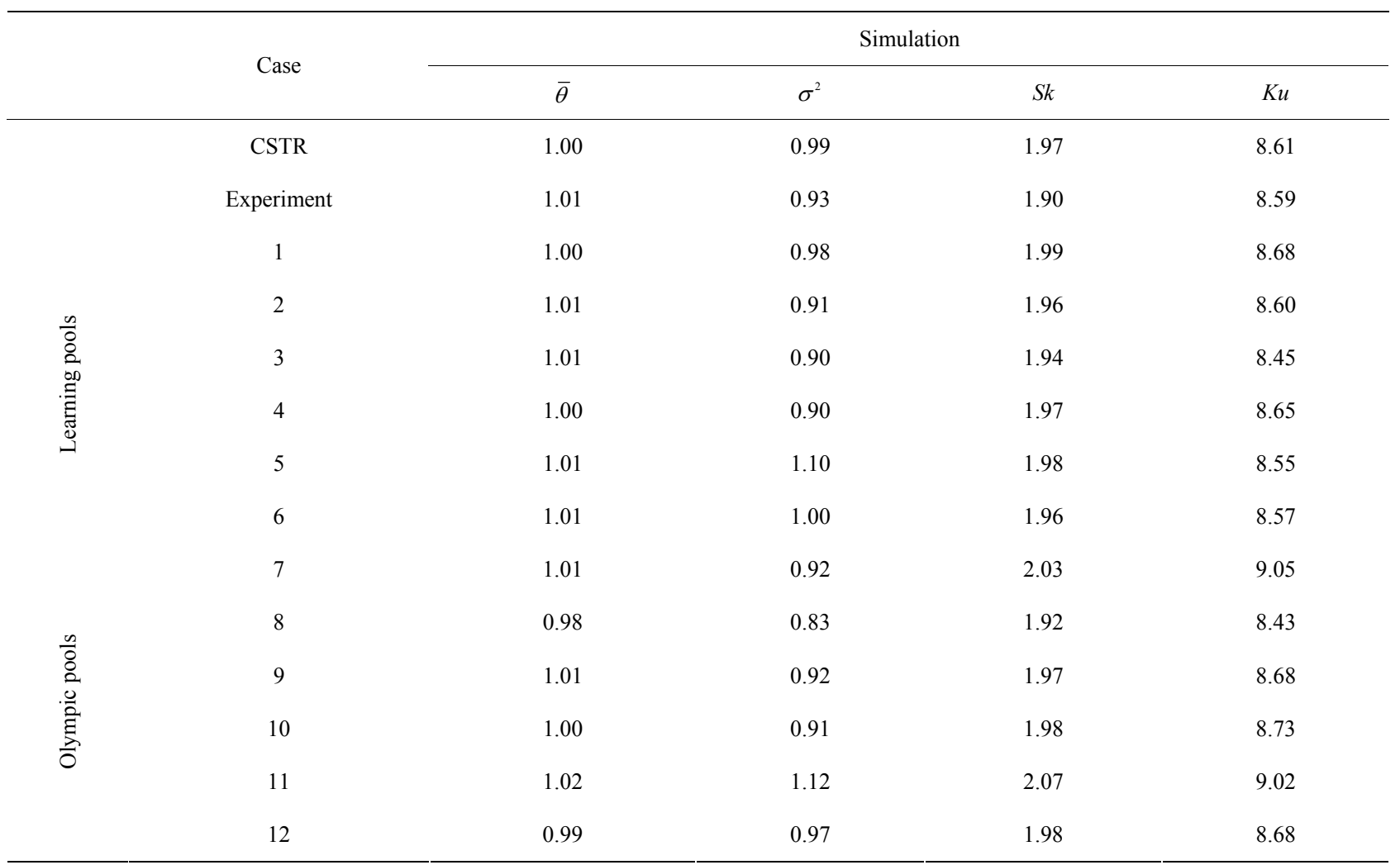




\subsubsection{Outlet Homogeneity Degree and Segregation Intensity}

The outlet homogeneity degree refers to a local concentration. In contrast, segregation intensity is calculated with a field of concentrations in the whole pool. These two signals were monitored for closed loop simulations.

The outlet homogeneity degree for the pools studied is illustrated in Figure 16. As for RTD for open loop configurations, the $U(\theta)$ curves for mixed hydraulics pools reveal the presence of significant short-circuits (Figure 16, lower panel). This could be because inlets

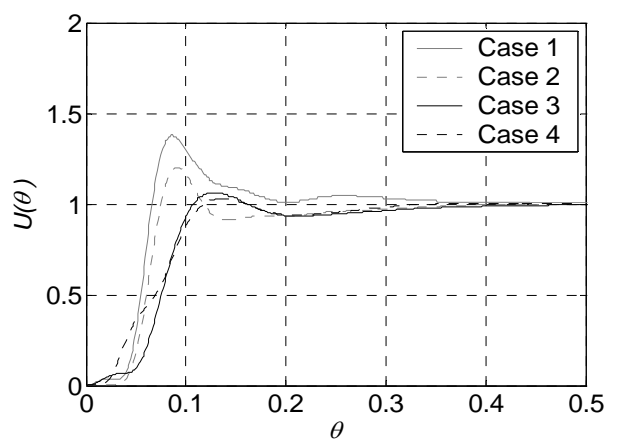

(a)

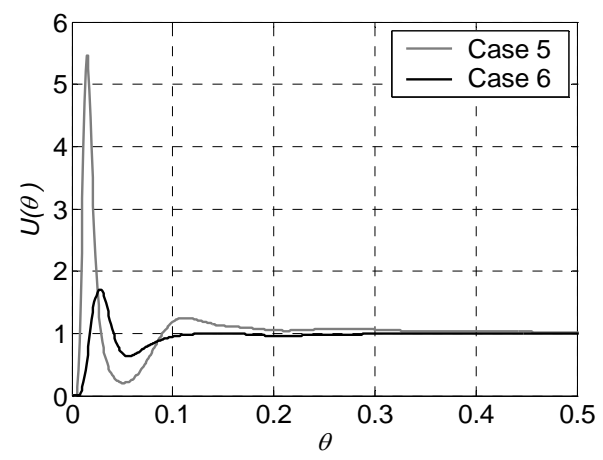

(c) are located too close to the surface, and outlets at the bottom of the pool create a preferential back flow of water. For a given hydraulics, oscillation amplitudes are greater for facing inlets than for staggered inlets.

Closed loop simulation reveals that the outlet concentration reaches its steady-state level after around $0.2 \tau$ in all cases (Table 5).

Numerical simulation also allows segregation intensity variations to be calculated in the whole pool volume for each configuration (Figure 17).

The 5\% mixing time, $\theta_{I S 5 \%}$, is between 0.27 and 0.56 ,

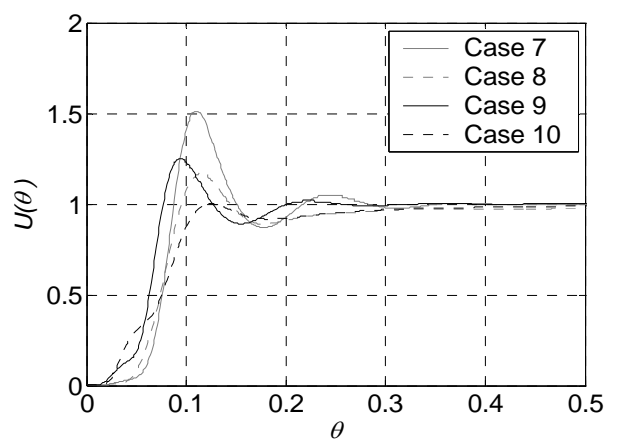

(b)

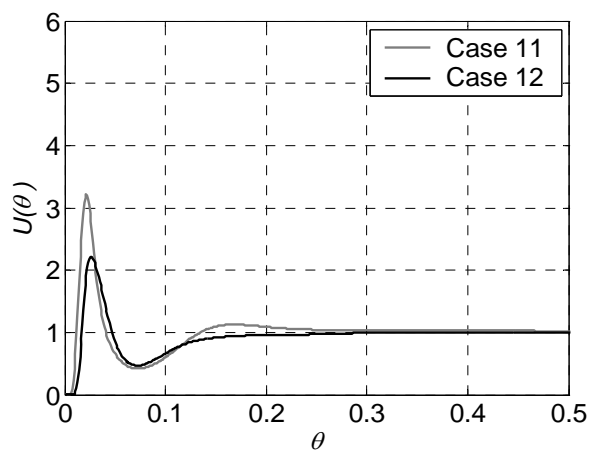

(d)

Figure 16. Outlet homogeneity degree in closed loop configurations: (a) Learning pools; (b) Olympic pools.

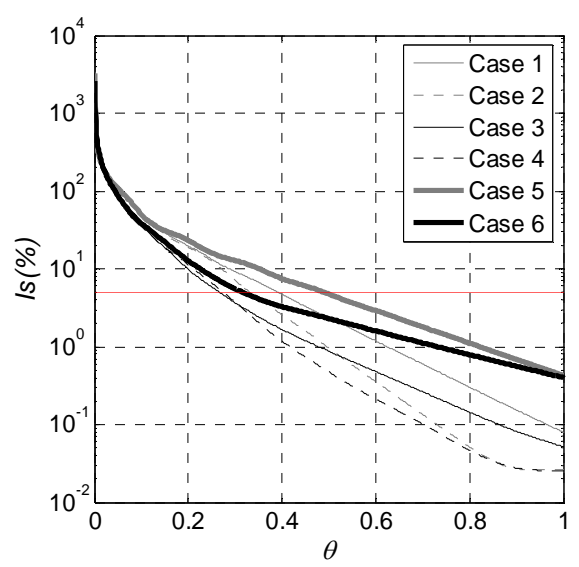

(a)

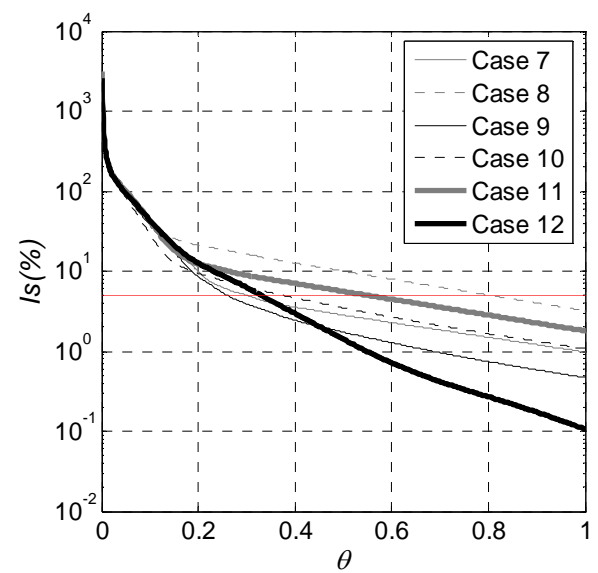

(b)

Figure 17. Segregation intensity in closed loop configuration: (a) Learning pools; (b) Olympic pools. 
i.e., between 2800 and $6000 \mathrm{~s}$ for designed pools (Table 5). Longer segregation times are obtained for pools with mixed hydraulics combined with facing inlets. The significant short-circuit observed in these configurations can explain impaired pool mixing. With staggered inlets, segregation intensity decreases faster than with facing inlets. This is consistent with previous observations of velocity fields (Figures 11 and 12). All the designed pools studied have a shorter mixing time, $\theta_{I S 5 \%}$, than the experimental pool. The outlet homogeneity degree, $\theta_{U 5 \%}$, however is close for both pool types.

The differences between simulated signals $U(\theta)$ for three Olympic pool geometries (Cases 7, 9 and 11) with and without buffer tank are presented in Figure 18. It appears that the amplitude of signal oscillations is not affected much by the buffer tank. However, it slightly increases the delay, particularly for Cases 7 and 9 .

\section{Conclusions}

This work highlights how swimming pool design affects hydraulic behavior, based on data from experimental and CFD studies. This paper is not intended to describe the hydraulic behavior of all existing swimming pools.

However, the cases studied are representative of existing pools found in Europe and the United States. These pools are designed based on criteria set out in fairly stringent standards. The experimental results validated

Table 5. Characteristic times for closed loop simulations.

\begin{tabular}{|c|c|c|c|c|}
\hline & \multirow{2}{*}{ Case } & \multirow{2}{*}{$\tau(\mathrm{h})$} & \multicolumn{2}{|c|}{ Simulation } \\
\hline & & & $\theta_{U 5 \%}$ & $\theta_{I S 5 \%}$ \\
\hline & Experiment & 1.98 & 0.16 & 1.21 \\
\hline \multirow{6}{*}{ 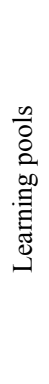 } & 1 & 3.0 & 0.27 & 0.39 \\
\hline & 2 & 3.0 & 0.23 & 0.33 \\
\hline & 3 & 3.0 & 0.26 & 0.27 \\
\hline & 4 & 3.0 & 0.24 & 0.28 \\
\hline & 5 & 3.0 & 0.31 & 0.49 \\
\hline & 6 & 3.0 & 0.10 & 0.32 \\
\hline \multirow{6}{*}{ 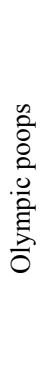 } & 7 & 3.0 & 0.21 & 0.30 \\
\hline & 8 & 3.0 & 0.26 & 0.80 \\
\hline & 9 & 3.0 & 0.18 & 0.26 \\
\hline & 10 & 3.0 & 0.25 & 0.38 \\
\hline & 11 & 3.0 & 0.23 & 0.55 \\
\hline & 12 & 3.0 & 0.18 & 0.33 \\
\hline
\end{tabular}

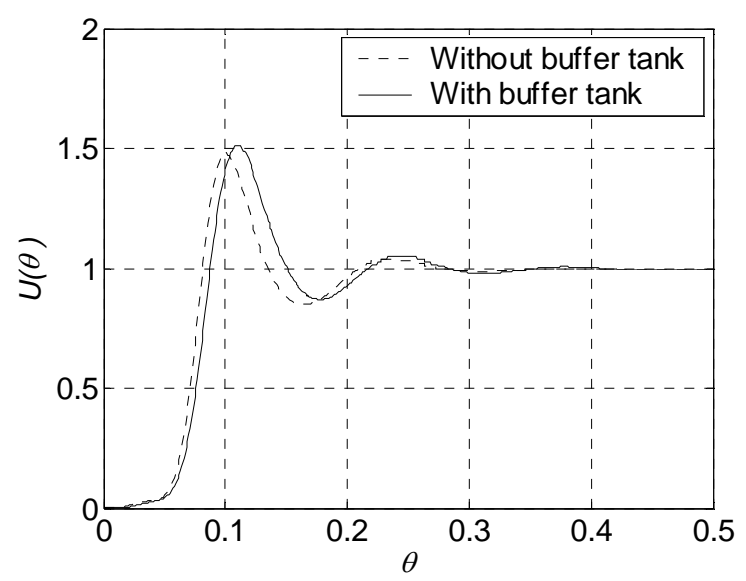

(a)

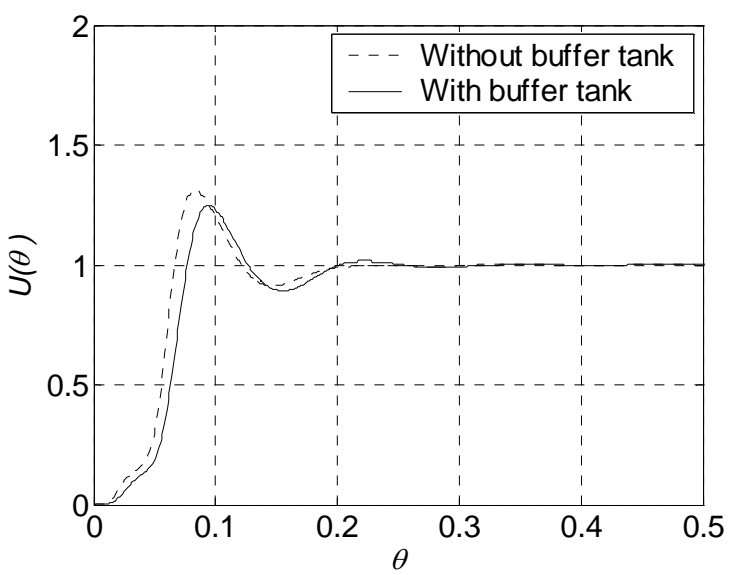

(b)

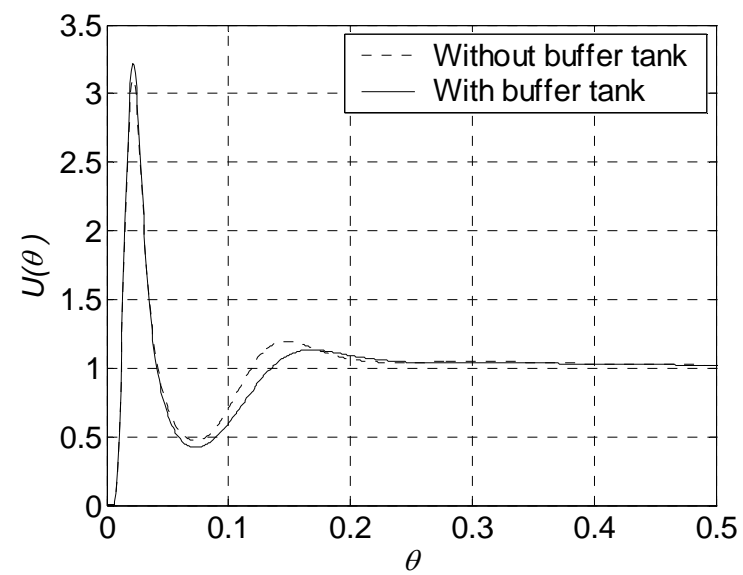

(b)

Figure 18. Outlet homogeneity degree in closed loop configuration (a) Case 7; (b) Case 9; (c) Case 11.

the CFD conditions. Simulation allowed water flow to be characterized for one experimental pool and 12 designed pools. This revealed average velocity field and stream lines, as well as the corresponding RTD and mixing ability. From these observations, the model developed, based on the principle of a continuous stirred reactor, could be 
used as a first approach to describe the hydraulic behavior of different pools. This model is suitable for the study of physical and chemical phenomena with long characteristic times e.g. urea chlorination [3]. Other, more advanced models will be better for the study of fast processes such as reaction scheme for chlorination of ammoniacal water [5]. The CSTR model can be extrapolated to pools with similar geometric configurations and operating modes to the pools studied, without requiring a CFD approach. This would be particularly convenient for kinetic applications, including prediction of chemical species concentrations in the pool, or to optimize chlorination and daily water renewal. Beside it is important to remember that this study has been performed in the absence of swimmers. Pool attendance should increase water mixing, accentuating resemblance to a stirred tank reactor. Further studies will be required to assess how the height or number of inlets affects pool mixing.

\section{REFERENCES}

[1] World Health Organization, "Guidelines for Safe Recreational Water Environments-Volume 2: Swimming Pools and Similar Environments," World Health Organization, Geneva, 2006.

[2] Afsset, "Sanitary Risks in Swimming Pools-Evaluation of the Sanitary Risks in Swimming Pools-Part 1: Regulated Pools," Scientific Edition, Water and Biological Agents, 2010.

[3] J. Li and E. R. Blatchley III, "Volatile Disinfection ByProduct Formation Resulting from Chlorination of Organic-Nitrogen Precursors in Swimming Pools," Environmental Science \& Technology, Vol. 41, No. 19, 2007, pp. 6732-6739. doi:10.1021/es070871+

[4] W. A. Weaver, J. Li, Y. L. Wen, J. Johnston, M. R. Blatchley and E. R. Blatchley III, "Volatile Disinfection By-Product Analysis from Chlorinated Indoor Swimming Pools," Water Research, Vol. 43, No. 13, 2009, pp. 33083318. doi:10.1016/j.watres.2009.04.035

[5] C. T. Jafvert and R. L. Valentine, "Reaction Scheme for the Chlorination of Ammoniacal Water," Environmental
Science \& Technology, Vol. 26, No. 3, 1992, pp. 577-586. doi: $10.1021 / \mathrm{es} 00027 \mathrm{a} 022$

[6] K. Ozekin, R. L. Valentine and P. J. Vikesland, "Modeling the Decomposition of Disinfecting Residuals of Chloramine," ACS Symposium Series, Vol. 649, 1996, pp. 115-125.

http://pubs.acs.org/doi/abs/10.1021/bk-1996-0649.ch008

[7] Y. Liu and J. Ducoste, "Numerical Simulation of Chloramines Formation in Turbulent Flow Using a Multi-Fluid Micromixing Model," Environmental Modelling \& Software, Vol. 21, No. 8, 2006, pp. 1198-1213. doi:10.1016/j.envsoft.2005.06.007

[8] A. I. Stamou, "Improving the Hydraulic Efficiency of Water Process Tanks Using CFD Models," Chemical Engineering and Processing: Process Intensification, Vol. 47, No. 8, 2008, pp. 1179-1189. doi:10.1016/j.cep.2007.02.033

[9] FINA, 2009. http://www.fina.org/

[10] ANSI, “ANSI/NSPI-1 (2003) Standard for Public Swimming Pools," 2003. www.webstore.ansi.org

[11] Swiss Standard, "Water and Plant Regeneration of water in Public Swimming Pools," SIA Swiss Society of Engineers and Architects, Zurich, 2000.

[12] T. W. Zhang, T. F. Wang and J. F. Wang, "Mathematical Modeling of the Residence Time Distribution in Loop Reactors," Chemical Engineering and Processing: Process Intensification, Vol. 44, No. 11, 2005, pp. 1221-1227. doi:10.1016/j.cep.2005.05.001

[13] M. Alliet-Gaubert, R. Sardeing, C. Xuereb, P. Hobbes, B. Letellier and P. Swaels, "CFD Analysis of Industrial Multi-Staged Stirred Vessels," Chemical Engineering and Processing: Process Intensification, Vol. 45, No. 5, 2006, pp. 415-427. doi:10.1016/i.cep.2005.11.003

[14] B. E. Launder and D. B. Spalding, "Lectures in Mathematical Models of Turbulence," Academic Press, Waltham, 1972.

[15] C. R. Wilke and P. Chang, "Correlation of Diffusion Coefficients in Dilute Solutions," AIChE Journal, Vol. 1, No. 2, 2004, pp. 264-270. doi:10.1002/aic.690010222

[16] Ansys, "Fluent," 2009. www.ansys.com/support/documentation 


\section{Nomenclature}

$c$ tracer concentration $\left(\mathrm{mol} \cdot \mathrm{m}^{-3}\right)$

$c^{\text {stat }}$ steady-state tracer concentration $\left(\mathrm{mol} \cdot \mathrm{m}^{-3}\right)$

$\bar{c}$ average tracer concentration $\left(\mathrm{mol} \cdot \mathrm{m}^{-3}\right)$

$d_{h}$ inlet hydraulic diameter $(\mathrm{m})$

$D$ molecular diffusivity coefficient $\left(\mathrm{m}^{2} \cdot \mathrm{s}^{-1}\right)$

$D_{T}$ turbulent diffusivity coefficient $\left(\mathrm{m}^{2} \cdot \mathrm{s}^{-1}\right)$

$e_{i} \quad$ distance between inlets $(\mathrm{m})$

$e_{o} \quad$ distance between bottom outlets $(\mathrm{m})$

$h$ pool depth $(\mathrm{m})$

$h_{i} \quad$ distance between inlets and pool bottom $(\mathrm{m})$

$k$ turbulent kinetic energy per unit mass $\left(\mathrm{m}^{2} \cdot \mathrm{s}^{-1}\right)$

$L$ pool length, (m)

$s \quad$ Laplace variable $\left(\mathrm{s}^{-1}\right)$

$t$ time (s)

$u$ inlet velocity $\left(\mathrm{m} \cdot \mathrm{s}^{-1}\right)$

$V$ volume $\left(\mathrm{m}^{3}\right)$

$V_{B T}$ water volume in buffer tank $\left(\mathrm{m}^{3}\right)$

$\dot{V} \quad$ volumetric flow rate $\left(\mathrm{m}^{3} \cdot \mathrm{s}^{-1}\right)$

$W$ pool width $(\mathrm{m})$

\section{Symbols}

$\varepsilon \quad$ turbulent kinetic energy dissipation rate per mass unit $\left(\mathrm{m}^{2} \cdot \mathrm{s}^{-3}\right)$

$\mu \quad$ liquid molecular viscosity $(\mathrm{Pa} \cdot \mathrm{s})$

$\mu_{T}$ turbulent viscosity $(\mathrm{Pa} \cdot \mathrm{s})$

$\mathcal{N}$ tracer quantity $(\mathrm{mol})$

$\rho$ water density $\left(\mathrm{kg} \cdot \mathrm{m}^{-3}\right)$
$\tau=V / \dot{V}$, turnover period $(\mathrm{s})$

$\tau_{B T}$ mean residence time in buffer tank (s)

Indices

$i$ inlet

$o$ outlet

Dimensionless numbers

$C_{1} \quad k-\varepsilon$ model constant

$C_{2} \quad k-\varepsilon$ model constant

$C_{\mu} \quad k-\varepsilon$ model constant

$C=V c / \mathcal{N}$, dimensionless concentration

$\mathrm{d} \theta$ dimensionless time step

$\delta$ dirac

$E$ residence time distribution

$f$ transfer function

$I \quad$ turbulence intensity

$I_{S} \quad$ segregation intensity

$K u$ kurtosis

$\mu_{k} \quad k$ order moment

$\mu_{k}^{\prime}$ centered $k$ order moment

$\theta=t / \tau$, dimensionless time

$\bar{\theta} \quad$ dimensionless average residence time

$\operatorname{Re}=\rho u d_{h} / \mu$, inlet jet Reynolds number

$\sigma^{2}$ variance of residence time distribution

$S c=\mu / \rho D$, laminar Schmidt number for tracer

$S c_{T}=\mu_{T} / \rho D_{T}$, turbulent Schmidt number for tracer

Sk skewness

$U$ outlet homogeneity degree 